\title{
A Study of Effect of the Socioeconomic Status on Asthma Management in Children in South India
}

\author{
Aparna Gulvadi', Sreenivasan V K'르. Ramaraj $\mathrm{S}^{3}$ \\ ${ }^{1}$ Associate Professor, Department of Paediatrics, Amala Institute of Medical Sciences, Trichur, Kerala, India, ${ }^{2}$ Associate Professor, Amala Institute of Medical \\ Sciences, Trichur, Kerala, ${ }^{3} \mathrm{Head}$ of department of Paediatrics \& Professor, Amala Medical college, Trichur, Kerala.
}

\section{Abstract}

Background: Asthma is a chronic and potentially serious condition with most children developing it at an early age. Every decade globally the prevalence is increasing by 50\%. Long term management focuses on preventing acute exacerbations, emergency attendances, hospitalizations, morbidity and mortality. Control of asthma is achieved by long term inhalers and by preventing the risk factors. Various risk factors influence the variation in prevalence and the long term outcome. Socioeconomic status (SES) is considered a major risk factor and is linked to various health outcomes especially in chronic diseases. Aim: To study the effect of SES on long term management of childhood asthma. Subjects and Methods: 500 parents of children attending the asthma outpatient clinic in a medical college were interviewed. Results: Based on the Revised Kuppuswamy's SES scale it was noted that $1.4 \%$ were upper class,33.6\% upper middle,47\%lower middle, $18 \%$ lower class. Our data revealed that parents from lower SES are unaware of diagnosis (0\%), are reluctant to accept diagnosis $(26.6 \%)$, reluctant to start inhalers (84.4\%) in comparison to upper and middle classes. Conclusion: Failure to diagnose asthma, lack of awareness of disease, poor understanding of the chronicity, and failure to initiate early inhaler therapy and poor adherence to inhalers was significantly noted in children from low socioeconomic background and this can adversely affect the long term outcome.

Keywords: childhood asthma, socioeconomic status, inhaler therapy.

Corresponding Author: Dr. Sreenivasan V K, Associate Professor, Amala Institute of Medical Sciences, Trichur, Kerala. Email: aparnagulvadi@gmail.com

Received: January 2020

Accepted: January 2020

Introduction

Asthma is one of the most prevalent, chronic diseases among children, globally affecting at least 7-10\% of world's population with almost $50 \%$ cases developing early by 10 years of age. There is $50 \%$ increase in prevalence every decade ${ }^{[1]}$.It is a disorder of airways characterised by reversible airway obstruction, airway inflammation and hyperactivity in response to various stimuli and pollutants. Despite advances in diagnosis and treatment, this condition is known for its sudden acute exacerbations, frequent emergency attendances and hospitalizations, sometimes needing intensive care. It is also associated with long term morbidity and worsening pulmonary functions. There is significant functional impairment with school absenteeism, limitation of activities, disruptions to family life and loss of working hours for parents. ${ }^{[2]}$ Thus the quality of life is significantly affected. There is rising treatment costs with financial burden to the health care system. Fortunately if detected early, asthma can be effectively treated and most patients will achieve good control in the long term. When asthma is well controlled there are no troublesome symptoms, no flare-ups, there is minimal need for reliever medication and children can lead productive, physically active lives with near -normal lung functions. But due to various ongoing risk factors, asthma patients get exacerbations with frequent worsening and loss of control of symptoms even if previously well controlled. These need to be recognised to prevent treatment failure and prevent long term morbidity. ${ }^{[2]}$

The presence of asthma and atopy in family members(especially maternal history of asthma) is one of the many risk factors reported in literature. ${ }^{[3]}$ Despite this considerable genetic contribution there are other additional social and environmental factors in the cause and exacerbation of childhood asthma. ${ }^{[4]}$ Several studies have tried to explain how low socio-economic status influences the development of asthma but with discrepant results. Most studies have shown children in families with low SES(measured by parental education, occupation and income) have an increased risk of asthma after adjustment of other variables ${ }^{[5,6,7]}$ Other studies found no relationship with parental SES. ${ }^{[8,9,10]}$ These diverse results could have been due to different study designs, small sample sizes or varying measures of SES. ${ }^{[1]}$

GINA guidelines currently state the need for long term controller therapy with use of inhaled corticosteroids(ICS) and leukotriene receptor antagonists(LRTA) for asthma control and for step wise management in under 5 wheezes ,children wheezing aged 6-12 years and those above 12 years. ${ }^{[2]}$ To achieve long term control all risk factors need to 
be considered. SES of asthmatic children is one such risk factor which can strongly influence the quality of care and asthma control.

The objective of this study is to evaluate the effect of SES in management of asthmatic children in a tertiary medical centre in South India.

\section{Subjects and Methods}

This descriptive study was conducted over a 4 year period from 2013 to 2017 at pediatric asthma clinic at Amala institute of medical sciences, Trichur, Kerala. Parents of 500 asthmatic children attending this clinic were enrolled.

\section{Inclusion Criteria}

Parents of children between 2-16 years diagnosed to have asthma. These children had at least 4 documented episodes of wheezing with at least 2 episodes in previous 6 months.

\section{Exclusion Criteria}

Wheeze associated with cardiac diseases, bronchiectasis, and children with other chronic lung diseases like cystic fibrosis.

Informed consent was obtained. Interview was conducted by a principal investigator with questions designed to elicit spontaneous responses. Questions dealt with the level of education and occupation of the head of the family and total family income. Per capita income was calculated. Questions dealt with family history of allergic disease, parental awareness of diagnosis of asthma and their acceptance of the same. Treatment details regarding use of inhalers were noted in already diagnosed patients.

Statistical Analysis: was performed by chi-square test.

\section{Results}

Following were the results: The socio-demographic characteristics of the participants are shown in [Table-1] $63.2 \%$ were male children and $36.8 \%$ female. Of the participants $82 \%$ were mothers, $5 \%$ were fathers and $13 \%$ both parents were present. Revised Kuppuswamy's scale for Socioeconomic Status was applied and scoring done based on 3 criteria: education of head of the family, occupation of head of the family and total per capita family income per

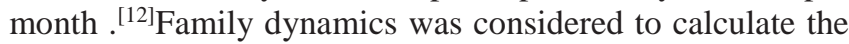
per capita income based on total family monthly income.[Table -2]100\% parents were literate.89\% mothers had studied beyond $\mathrm{X}^{\text {th }}$ standard and $75 \%$ fathers had studied beyond $\mathrm{X}^{\text {th }}$ standard and further categorized based on Modified Kuppuswamy's Scale. Occupation of head of the family was categorized as unemployed, unskilled worker, semi-skilled worker, skilled worker, and clerical/shop/farm, semi professional and professional. Scoring based on income was done by using the revised AICPI 2017(All India Consumer Price Index).By the revised Kuppuswamy's SES ${ }^{[13,14]} 1.4 \%$ were upper class, $33.6 \%$ upper middle, $47 \%$ lower middle and $18 \%$ were lower class [Table-3]. $80 \%$ families were from urban area and $20 \%$ were from semi-urban, no families from rural area were noted in this study.

Table 1: Socio-demographic characteristics (n=500)
\begin{tabular}{|l|l|l|}
\hline Variables & Results & \\
\hline Gender of children & Male & $316(63.2 \%)$ \\
\hline & Female & $184(36.8 \%)$ \\
\hline Gender of parents & Mothers & $410(82 \%)$ \\
\hline & Fathers & $25(5 \%)$ \\
\hline & Both present & $65(13 \%)$ \\
\hline $\begin{array}{l}\text { Education status of } \\
\text { parents }\end{array}$ & & \\
\hline Fathers & $<\mathrm{X}^{\text {th }}$ standard & $375(75 \%)$ \\
\hline & $>\mathrm{X}^{\text {th }}$ standard & $125(25 \%)$ \\
\hline Mothers & $<\mathrm{X}^{\text {th }}$ standard & $55(11 \%)$ \\
\hline & $>\mathrm{X}^{\text {th }}$ standard & $455(89 \%)$ \\
\hline
\end{tabular}

Table 2: Family dynamics and marital status

\begin{tabular}{|l|l|l|}
\hline Family dynamics & Joint family & $346(69.2 \%)$ \\
\hline & Number of members & \\
\hline & $<5$ & $280(80.9 \%)$ \\
\hline & $>6$ & $66(19.1 \%)$ \\
\hline Marital status & Nuclear family $<4$ & $154(30.8 \%)$ \\
\hline & Married & $491(98.2 \%)$ \\
\hline & Divorced & $5(1 \%)$ \\
\hline & Widow/widower & $4(0.8 \%)$ \\
\hline
\end{tabular}

Table 3: A Socio-economic class

\begin{tabular}{|l|l|l|}
\hline Total score & Class & Number $(\%)$ \\
\hline $26-29$ & Upper class & $7(1.4 \%)$ \\
\hline $16-25$ & Upper middle & $168(33.6 \%)$ \\
\hline $11-15$ & Lower middle & $235(47 \%)$ \\
\hline$<10$ & Lower & $90(18 \%)$ \\
\hline
\end{tabular}

Table 4: Family history of allergic disorders based on SES (380/500)

\begin{tabular}{|l|l|l|l|}
\hline SES & Yes & No & Total (\%) \\
\hline Upper & 3 & 4 & $7(42.8 \%)$ \\
\hline Upper middle & 155 & 13 & $168(92.2 \%)$ \\
\hline Lower middle & 177 & 58 & $235(75.3 \%)$ \\
\hline Lower & 45 & 45 & $90(50 \%)$ \\
\hline *p value(chi square $<0.0001)$
\end{tabular}

Table 5: A Parental awareness based on SES

\begin{tabular}{|l|l|l|l|}
\hline SES & Aware & Unaware & Total (\%) \\
\hline Upper & 5 & 2 & $7(71 \%)$ \\
\hline Upper middle & 118 & 50 & $168(70.2 \%)$ \\
\hline Lower middle & 57 & 178 & $235(24.2 \%)$ \\
\hline Lower & 0 & 90 & $90(0 \%)$ \\
\hline
\end{tabular}

$*$ p value(chi square $<0.0001)$

Table 6: Parental acceptance based on SES

\begin{tabular}{|l|l|l|l|}
\hline SES & Acceptance & Reluctant & Total (\%) \\
\hline Upper & 7 & 0 & $7(100 \%)$ \\
\hline Upper middle & 144 & 24 & $168(85.7 \%)$ \\
\hline Lower middle & 150 & 85 & $235(63.8 \%)$ \\
\hline Lower & 24 & 66 & $90(26.6 \%)$ \\
\hline
\end{tabular}

*p value (chi square<0.0001)

Table 7: Parental understanding of the nature of illness based on SES (Aetiology, chronicity and course of disease)

\begin{tabular}{|l|l|l|l|}
\hline SES & Aware & Unaware & Total (\%) \\
\hline Upper & 4 & 3 & $7(57 \%)$ \\
\hline Upper middle & 144 & 24 & $168(85.7 \%)$ \\
\hline Lower middle & 150 & 85 & $235(63.8 \%)$ \\
\hline Lower & 0 & 90 & $90(0 \%)$ \\
\hline
\end{tabular}


Table 8: Children already on inhalers based on SES (73/500)

\begin{tabular}{|l|l|l|l|}
\hline SES & On inhalers & Not on inhalers & Total (\%) \\
\hline Upper & 3 & 4 & $7(42 \%)$ \\
\hline Upper middle & 50 & 118 & $168(29.7 \%)$ \\
\hline Lower middle & 20 & 215 & $235(8.4 \%)$ \\
\hline Lower & 0 & 90 & $90(0 \%)$ \\
\hline
\end{tabular}

*p value (chi square $<0.0001$ )

Table 9: Reluctance to start inhalers based on SES

\begin{tabular}{|l|l|l|l|}
\hline SES & Willing & Reluctant & Total (\% reluctant) \\
\hline Upper & 4 & 0 & $4(0 \%)$ \\
\hline Upper middle & 95 & 23 & $118(19.4 \%)$ \\
\hline $\begin{array}{l}\text { Lower } \\
\text { middle }\end{array}$ & 97 & 118 & $215(54.8 \%)$ \\
\hline Lower & 14 & 74 & $88(84 \%)$ \\
\hline
\end{tabular}

*p value (chi square $<0.0001)$

\section{Discussion}

Asthma is a common chronic recurring inflammatory disorder with a rising prevalence noted even in children. Due to its recurring nature the patient has frequent exacerbations with emergency attendances, hospitalizations and sometimes intensive care management. The treatment is directed towards managing the acute severe asthma, controlling the disease to improve quality of life of the child and family and preventing further exacerbations and morbidity. There are various risk factors implicated in aetiopathogenesis of asthma and several risk factors are known for inadequate asthma control and progression of the disease despite treatment having been initiated. ${ }^{[4]}$ Socioeconomic status of a family is considered as a major contributor to development of asthma and also inadequate disease control. However various studies have shown discrepant results.

Hence we analyzed the socioeconomic status in the families of children attending the asthma outpatient department regularly in our medical college and studied its association with different variables. A detailed analysis of family history of any of the allergic disorders, parental awareness of the disease, their acceptance of the diagnosis and general understanding of the disease was made. The number of children already on inhalers was noted. Reluctance to start on inhalers among the parents of those children not on inhalers was also noted.

Majority of our patients belonged to middle class $(80.6 \%)$, upper class were $1.4 \%$ and lower class were $18 \%$.Family history of allergic conditions was mentioned positive in total 380 cases. $50 \%$ of the lower class denied any family history of allergic disorder. Among the other classes, family history was positive in upper class (3/7), upper middle class $(155 / 168)$; lower middle $(177 / 235)$. This difference between the lower class and other 3 classes is statistically significant ( $p$ value $<0.0001$ ). This may be a significant risk factor considering the ignorance among the parents of low SES in recognizing the symptoms pointing towards asthma and also causing a delay in seeking appropriate medical attention for their children. Previous study has shown positive family history as a major risk factor which disproportionately affects the outcome in children from low SES ${ }^{[15]}$.Also being aware of positive family history helps the parents to easily accept that child could be suffering from asthma ${ }^{[16]}$.Only $36 \%$ of parents were aware about the diagnosis of asthma. The difference between the low SES and other 3 classes (upper, uppermiddle, lower middle) is statistically significant ( $p$ value $<0.0001)$. None of the parents of the low SES $(0 \%)$ were aware as compared to upper (71\%), upper middle(70.2\%),lower middle(24.2\%) class .The lack of awareness of correct diagnosis is significant as undiagnosed asthma children have a poor long term prognosis .Hence a better physician parent communication is needed to obtain a detailed history of family members with regards to the presence of atopic conditions and a subsequent evaluation to confirm the diagnosis of asthma in the child.

$65 \%$ of parents were willing to accept the diagnosis .Only $26.6 \%$ of the lower SES accepted but $100 \%$ of upper, $85.7 \%$ of upper middle and $63.8 \%$ of lower middle class accepted the diagnosis. This difference is statistically significant. This implies that parents from low SES are unaware of the diagnosis. There is also a delay in seeking appropriate treatment as there is denial of illness. A study in 1995 in North India showed a significant correlation with low SES and middle SES and hesitancy in seeking adequate treatment for asthma as it was considered as a social stigma and there was associated denial. ${ }^{[17]}$

Detailed enquiry regarding overall understanding of this disease regarding aetiology, course of disease, precipitating factors and long term prognosis revealed statistically significant difference between the low SES $(0 \%$ unaware) and upper (100\%),upper middle $(85.7 \%)$ lower middle $(63.8 \%)$.

75 children were on inhalers and were from upper, upper middle and lower middle class. This number is similar to a study from Chennai ${ }^{[16]}$ The low SES class children were not on any inhalers and this was statistically significant ( $\mathrm{p}$ value $<0.0001)$.A statistically significant difference among the low SES and other classes was also noted in their reluctance to initiate inhalers once diagnosis was made and parents needed counseling for the same.

Our study has revealed that children from low SES form a significant number of children that fail to get adequate asthma treatment .Parents from this SES are unaware of the positive family history, unaware of diagnosis and are reluctant to accept the diagnosis. There is a clear documentation regarding the positive influence the role of educating parents about the disease has for accepting the diagnosis and for the subsequent compliance in asthma management. ${ }^{[18]}$ Low SES has been linked to higher morbidity as these patients could have several indices of worse asthma morbidity particularly worse asthma 
control, independent of disease severity .These adverse outcomes are linked to increased exposure to indoor and outdoor allergens and tendency to use less inhaled corticosteroids thus increasing the risk of exacerbations ${ }^{[19]}$.Previous studies have also shown significant associations between low childhood SES, poor health behavior patterns and increased prevalence of asthma ,severe asthma, increased emergency visits and hospitalizations for asthma attacks ${ }^{[20,21,22]}$ In a previous study it has been demonstrated that the lower SES (low parental income and lesser education) is associated with lower use of inhaled medications and poor inhaler adherence even after treatment has been initiated indicating the need for continued surveillance in this group of children. Here the need for establishing specialized clinics and need to follow definite asthma guidelines has been mentioned. ${ }^{[23]}$

\section{Conclusion}

There is a definite association between parental SES and inadequate asthma management. Children from low SES fail to get asthma diagnosed early due to poor health seeking behavior patterns by the parents. Lack of parental awareness, failure in communication by the attending physician and delay in starting appropriate early preventive therapy has been documented. More attention should be paid to this SES with measures to target early diagnosis by establishing good asthma clinics at the primary health care centers with emphasis on regular follow up. Specialized measures to control pollutants and improve poor health behavior patterns are needed in this SES. This will help to improve the asthma outcome and reduce morbidity.

\section{Limitations}

As the study groups included only those attending the specialized asthma clinic, a study involving the children attending the general pediatric Out Patient department or from community should be considered. A further study analyzing the severity of asthma and its outcome with the SES should be considered.

\section{References}

1. Netuveli G, Hurwitz B, Levy M, Fetcher M,Barnes G, Durhan SR, Sheikh A. Ethnic variation in UK asthma frequency, morbidity and health service use: a systematic review and Meta -analysis. Lancet $2005 ; 365(9456): 312-317$.

2. The Global Initiative for Asthma. Pocket Guide for Asthma Management and Prevention.GINA, 2019.pg 7-15.

3. Martel MJ, Rey E, Malo JL, Perreault S, Beauchesne MF, et al: Determinants of the incidence of childhood asthma: a two-stage case-control study. American journal of epidemiology 2009; 169:195-205

4. Bao Y,Chen Z,Liu E,Xiang L,Zhao D,Hong J. Risk Factors in Preschool Children for Predicting Asthma During the Preschool and the Early School Age: a Systematic Review and Meta-Analysis.Curr
Allergy Asthma Rep 2017 Nov 18;17(12):85

5. 5.Kozyrskyj AL,Kendall GE,Jacoby P,Sly PD,Zubrick SR. Association between socioeconomic status and development of asthma :analysis of income trajectories. American journal of public health 2010; 100:540-546

6. 6.Lindbaek M,Wefring KW, Grangard EH, Ovsthus K. Socioeconomic conditions as risk factors for bronchial asthma in children aged 2-5 years .European Respiratory Journal 2003;21:105108

7. 7.Almqvist C, Pershagen G,Wickman M. Low socioeconomic status as a risk factor for asthma, rhinitis and sensitization at 4 years in a birth cohort. Clinical and experimental allergy: journal of the British Society for Allergy and Clinical Immunology 2005; 35; 612-618

8. Socioeconomic deprivation and asthma prevalence and severity in young adolescents. Poyser M A, Nelson H, Ehrilch RI, Bateman ED, Parnell S, Puterman A, Weinberg E. European Respiratory Journal 2002; 19:892-898

9. Hancox R J, Milne B J, Taylor D R, Greene J M, Cowan J O, et al. Relationship between socioeconomic status and asthma: a longitudinal cohort study. Thorax 2004; 59:376-380

10. Mitchell E A, Stewart AW, Patter more P K, Asher M I, Harrison $\mathrm{AC}$, et al Socioeconomic status in childhood asthma. International Journal of Epidemiology 1989; 18:888-890

11. Bravenman P A, Cubbin C, Egerter S, Chideya S, Marchi K S, et al. Socioeconomic status in health research: one size does not fit all. JAMA: the Journal of the American Medical Association 2005; 294:2879-2888.

12. 12.Aggarwal OP, Bhasin SK, Sharma AK,Chabbra P, Aggarwal K, Rajoura OP. A new instrument (scale) for measuring the socioeconomic status of a family: preliminary study. Indian $\mathrm{J}$ Community Med 2005; 30(4):111-114

13. Sharma R. Revised Kuppuswamy's Socioeconomic Status Scale .Explained and Updated. Indian Pediatrics 2017; 54:867-870

14. Sharma R. Online Interactive Calculator for Real-Time Update of the Kuppuswamy's Socioeconomic Status Scale .Available from www. Scaeupdate.weebly.com June 1, 2017

15. Burke W, Fesinmeyer M, Reed K, Hampson, Carlsten C. Family history as a predictor of asthma risk. American Journal of Preventive Medicine. Volume 24, Issue 2, Feb 2003; p160-169

16. Shivbalan S, Balasubramanian S, Anandnathan K. What do Parents of Asthmatic Children Know about Asthma? An Indian Perspective. The Indian Journal of Chest Diseases and Allied Sciences.2005; 47; 81-87

17. Lal A, Kumar L, Malhotra S. Knowledge of asthma among parents of asthmatic children. Indian Pediatrics 1995; 32:649-655

18. Mishra N, Rao KVR, Padhi S K. Asthma Education for Better Compliance in Disease Management: Indian J Allergy Asthma Immunology 2005; 19(1):25-28

19. Simon L Bacon, Anne Bouchard, Eric B Loucks and Kim L Lavoie. Individual-level socioeconomic status is associated with worse asthma morbidity in patients with asthma. Respiratory Research 10, Article number: 125(2009)

20. Mielck A, Reitmer P and West M .Severity of Childhood Asthma by Socioeconomic Status. International Journal of Epidemiology. 1996, 25:388-393

21. Cesaroni G, Farchi S, Davoli M, Forastiere F, Perucci CA. Individual and area based indicators of socioeconomic status and childhood asthma .Eur Resp J 2003, 22:619-624

22. Klinnert MD, Nelson HS, Price MR, Adinoff AD, and Leung DYM, Mrazek DA: Onset and Persistence of Childhood Asthma: Predictors from Infancy .Pediatrics 2001, 108; e69

23. Tong Gong, Lundholm C, Rejno G, Mood C, Langstrom N, Almqvist C. Parental Socio-economic Status, Childhood Asthma and Medication Use-A Population Based Study. PLoS ONE 9(9):e10659. 
Copyright: () the author(s), 2020. It is an open-access article distributed under the terms of the Creative Commons Attribution License (CC BY 4.0), which permits authors to retain ownership of the copyright for their content, and allow anyone to download, reuse, reprint, modify, distribute and/or copy the content as long as the original authors and source are cited.

How to cite this article: Gulvadi A, Sreenivasan V K, Ramaraj S. A Study of Effect of the Socioeconomic Status on Asthma Management in Children in South India. Asian J. Med. Res. 2020;9(1):PE01-PE05.

DOI: dx.doi.org/10.47009/ajmr.2020.9.1.PE1

Source of Support: Nil, Conflict of Interest: None declared. 